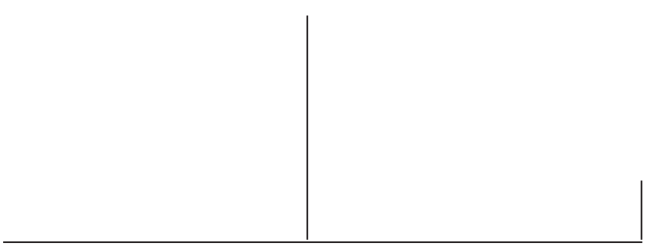

Rev. Latinoam. Psicopat. Fund., V, 1, 11-19

\title{
Assigning things to their proper class: taxonomic issues and trends in psychiatry
}

\author{
Cláudio Eduardo Muller Banzato
}

In this article the author examines some of the taxonomic challenges still facing diagnostic classification in psychiatry, especially those mentioned in Hempel's important work entitled Fundamentals on Taxonomy. New trends in research and classification are also discussed.

Key words: Classification, taxonomy, diagnosis,

psychiatry 
What physicians say of distinct species [of melancholy] in their books it much matters not, since that in their patient's bodies they are commonly mixed.

Robert Burton, The Anatomy of Melancholy (1621), p. 177

It has long been widely acknowledged that diagnostic classification in psychiatry is controversial in character. In fact, there's been always an uproar surrounding the fierce and never-ending arguments about its many facets. Thus, it is hardly surprising that we notice the frequent use of the military metaphor "battlefield" when referring to this subject. The launching of DSM-III added new fuel to the flames, and ever since 1980, conflict over what are the fundamentals in psychiatric nosology has become, in some respects, the order of the day. The initial emphasis placed on the reliability of diagnoses contributed a great deal to the shaping of the current scientific programme of psychiatry, even though the much more complex issue of validity has remained a challenge. The proof of this is that there is not a single psychiatric diagnostic category which has been entirely validated. Besides, some distinguished professionals share the view that despite many remarkable scientific advances, something in psychiatry has recently gone astray. (VAN PraAg, 1992; Feinstein, 2000)

The diagnostic categories, mostly based on correlations between symptoms, can be properly seen as hypotheses about class membership 


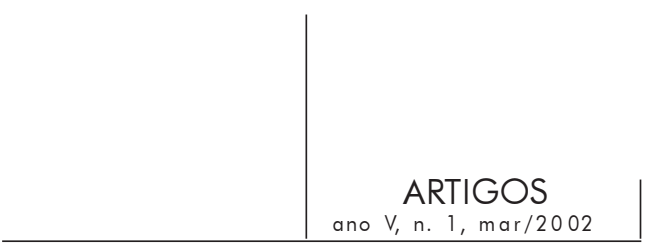

(Guimon, 1989). Diagnostic labels, on one level, represent useful clinical tools because they condense relevant information for practical purposes (despite an unavoidable loss of some of this information in the process). On another level, the taxonomical system that they can be formed into, provides us with a theoretical perspective on the field. These two functions should not conflict within the framework of a scientific nosology. However, completing a scientific nosology is definitely not an easy task: notwithstanding the strength of scientific method, many decisive nonempirical issues have to be faced beforehand (KENDLER, 1990).

The distinction between "fact" and "theory" is quite often considered as a selfevident one: fact is reputed as something which stands on its own, that means, no person in good faith would deny its independent and true existence, no matter her theoretical commitments. It seems worthwhile mentioning this naïve point of view because this assumption underlies much of the recent developments in psychiatric nosology. But it would not be entirely fair to blame DSMs for that - the golden rule of DSM-IV (as well as its two immediate predecessors) actually reads: stay close to data and minimize inference. It would be hard to find fault with this as it is just standard scientific procedure. The problem lies elsewhere: theorizing has been set aside for the time being and the age-old problem of lack of agreement about theory among psychiatrists was held responsible for this. It indeed prevents communication and therefore hinders the scientific progress of the discipline. However, it is a completely different matter to use this problem as basis for the conclusion that theory can be overlooked, even if only in the short-term.

What must be explored here is how psychopathological concepts inextricably intertwine with data. It is not our intention, however, either to challenge the empiricist's claims on his alleged building blocks of reality or to endorse any relativistic position. For us, it is crucial to understand that the boundaries between the conceptual and the matter of fact are quite fuzzy, as we believe that this might help to prevent, to some degree, dogmatism.

In psychiatry, a key problem to be tackled is the serious lack of specificity of most symptoms. This might explain the long-standing arbitrariness in the matter of diagnosis and classification. The much-expected biological markers, always on the horizon, have not been discovered yet. It is indeed arguable that they seem to be as elusive as ever. Despite the stability of the main diagnostic categories over the last century, they remain at best clusters of symptoms that exhibit to some extent a typical pattern of course and outcome. Their permanence is a clear sign of clinical utility of these constructs, rather than a proof of scientific rigour of the discipline. The ultimate scientific goal of psychiatry has been to isolate pure morbid forms, that is, to identify each member of a special group of natural kinds, the diseases. In other words, the underlying hope of researchers would be to find out a perfect match between the three levels of description: symptomatic, pathogenic and etiologic (Ріснот, 1994). 


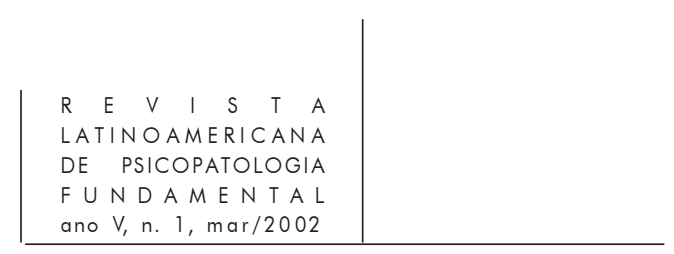

At this point, one difficulty must be indicated, that of the very possibility of separating a disease from its attributes. It is unsurprising therefore that many of our terms of art seem to oscillate between one sense and another. We suggest that in order to try to distinguish the symptomatic level from the morbid one some logical steps must be taken into account. Thus, let us consider first the differences between those overlapping elements that allow the constitution of a taxonomic category: definition and clinical attributes.

The definition of a taxonomic category itself can be based solely on clusters of symptoms or can otherwise be properly established on etiopathogenic grounds. In the former case, definition inevitably displays a conventional character, whereas in the latter it is supported by empirical evidence. However, this state of affairs is not as clear-cut as it may look at first sight because the degree of evidence can vary considerably. Besides, as the history of medicine illustrates so well, it is often just a matter of time before an invariable set of features turns into a definite nosologic entity. In medicine, the use of the language of the symptom usually implies the belief in the existence of a pathogenic process underneath, to which it is somehow related. The symptom (etymologically, what coincides) is an index, the visible side of a putative process. Thus, this hypothetical link has to be proven true and that is precisely the task of science: to confirm through independent means the presence of the pathogenic process from which the symptom has sprung and also to elucidate the mechanisms involved in the connection between them. In this sense, the symptom counts as inductive evidence in favour of a diagnostic category (BANZATO, 2000).

Nevertheless, in psychopathology it is not always an easy task to evince the presence of an isolated symptom itself. This is due to the fact that most of the symptoms are far from being, in any sense, elementary (SPITZER, 1988). The problem with symptoms in psychiatry rests on the fact that they often are not simple and discrete building blocks. Arguably, their identification can pose difficulties similar to those found in the determination of the condition they are thought to be a symptom of. For instance, does auditory hallucination appear to be more tangible than schizophrenia itself? Despite its diagnostic importance, the psychopathology of halluccination is still controversial as we find in clinical practice a wide range of closely related phenomena, with no clear-cut limits between them. It is true that many patients under clinical care exhibit, with regards to "hearing voices", the characteristic pattern outlined by Esquirol, whereas other equally disturbed and frightened patients just seem unable not to use the language of perception to think about and to communicate their strange experience. Perhaps they just cannot help describing their uncanny feeling in familiar terms.

Before discussing some taxonomic issues, it may be worthwhile perusing this enlightening classification of classifications, borrowed from Jablensky (1988): 


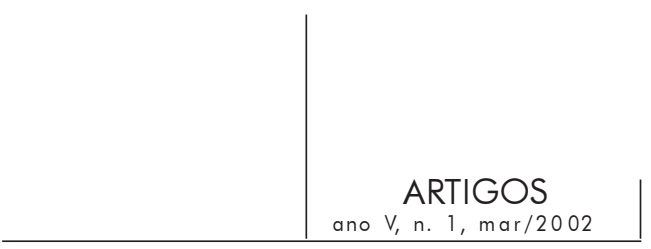

1. According to the taxonomic strategy:

a) phyletic (essentialist, natural classification $=$ true picture of the world)

b) phenetic (numerical taxonomy, emphasis on description of the appearance) 2. According to the type of cognitive operation involved:

a) empirical (intended to be strictly limited to observable facts)

b) inferential (makes guesses about possible underlying processes)

3. According to the end product:

a) monothetic (one organizing principle, limited to one or very few variables)

b) polythetic (based on a set of rules - it does not require necessarily any shared property between elements assigned to a given class)

It is interesting to mention in the first place the slight difference between classification and taxonomy: the former is a much broader term basically meaning some arrangement in classes, taking into account common characteristics or affinities exhibited by their members-to-be, whereas the latter has a more precise and scientific sense, it concerns a systematic classification built on general rules or principles. Thus, taxonomy appears to be more explicitly theory-bound. In other words, theory can be thought of as the glue that gives cohesion and relevance to classification (MILLON, 1991).

Although there seems to be certain elective affinities between some strategies and types of systems, this does not imply any necessary relation between them, however natural some of the resultant combinations appear to be. Besides, a classification may also represent a compromise, that is, different categories may be constituted through a variety of principles. Of course this procedure can help to settle hopeless disputes, but at the expense of the taxonomic appeal and strength of the classification itself.

Hempel in his influential Fundamentals of Taxonomy (paper read in 1959 and first published in 1961) addresses a few basic problems of the taxonomy of mental disorders. His chief concern is to establish the main functions of scientific concepts: empirical import (observational terms, on a descriptive level) and systematic import (law-like formulations, on a theoretical level). The predominance of one of these two functions would denote the development of a scientific discipline: a progressive shift from a descriptive stage to a theoretical one is the course of such a development. That would correspond in medical science to the transition from a symptomatological to a more etiological point of view.

The case Hempel examines more closely, however, is taken from chemistry. He deals with the fact that the elements potassium, sodium, cesium, rubidium and lithium were grouped together as alkali metals (because they share many characteristic chemical reactions) before the periodic system was actually proposed. This case is quite remarkable because the previous observational classification could be fully maintained within the framework of the later theoretical classification, based on the 


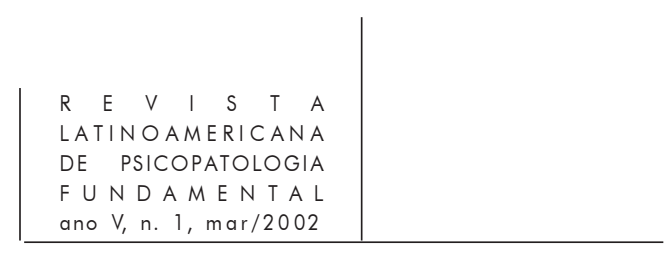

atomic structure of the elements (periodic system of Mendeleev). Unfortunately, it is not always so. For instance, when a shift like this (from observational-phenomenal to theoretical modes of defining and differentiating the elements) occurs in medicine, two individuals with similar symptoms can be assigned to utterly different diagnostic categories. Indeed, this seems to be a more likely outcome.

But this is not what really is at stake here. The logical empiricist philosopher Hempel intends to emphasize the necessary connection between concepts (theoretical constructs) and their clear-cut empirical (operational) ${ }^{1}$ criteria for the sake of applicability to concrete cases. In this sense, an operational criterion is just a symptom for whatever the given concept stands for, it by no means represents a full definition of the concept. On the one hand, the meaning or definition of concepts would depend ultimately on the theoretical system to which they belong, on the other, symptoms-criteria would link them up with the so-called empirical reality.

Although this model was implicitly adopted by mainstream psychiatry in the last decades, if we decide to judge our current classifications by Hempel's scientific standards, we will find, to our own dismay, that so little was achieved. After all, what can a set of operational criteria built on conceptual vacuum possibly mean? Once theory is cast aside, there are no more law-like formulations or systematic imports or predictions whatsoever. There remain just conventions, in other words, tautological definitions. Maybe it will be possible to escape from the strait-jacket we are willingly wearing if we try hard to look at psychopathological phenomena through another kind of lens.

In this sense, we are fortunate enough to have recently witnessed a step forward: a process of reappraisal of the conceptual commitments of current psychiatry may be starting. An important symposium on International Classification and Diagnosis, organized by the WHO Office on Classification, Assesment and Surveys and the WPA Section on Classification and Diagnostic Assesment, took place on 12-13 July 2001 at the WPA European Congress in London. ${ }^{2}$ Across the wideranging programme, which consisted of both a critical review of current systems of classification and a debate about future directions, special emphasis was laid on conceptual issues. And judging by the interest aroused during the airing of these issues, the decision to place such emphasis upon them could not have been more timely.

1. As we have seen before, due to the fact that halluccination remains such an elusive phenomenon, it is hardly the kind of operational criterion Hempel alludes to. Therefore, building a category on psychopathological constructs like this requires utmost caution.

2. The full text of the contributions presented at this symposium is expected to be published soon in Psychopathology. 


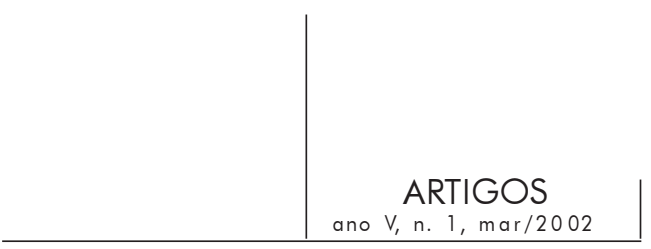

After the heat generated during the eighties in the dispute over DSM-III, the following decade may have seemed relatively quiet with regards to arguments about core concepts of diagnosis and classification. But this was hardly the whole story. What happened is better described as a shift in publication trends: papers on the subject migrated from the more influential psychiatric journals to the more interdisciplinary ones, as well as to newly edited reviews and books. At the present time however, the unexpected (to that extent) convergence exhibited by the international experts in the aforementioned symposium appears to signal another forthcoming change of direction. In order to provide support for such an interpretation, we will list below and very briefly comment on the main points that emerged at that event.

1) Both prevailing systems of classification (APA's DSM and WHO's ICD) decreed, for different set of reasons, a moratorium on revisions: DSM-V and ICD-11 are not therefore expected to come out before 2010. The WHO intends to concentrate efforts on better implementing ICD all over the world, whereas APA is mainly concerned with the loss of credibility that sucessive changes in categories without a solid scientific basis can produce.

2) Reliability is no longer to be regarded as the cornerstone of diagnostic classification. This issue is now held to be a matter of lesser significance, and one which we have learned to deal with in practical terms.

3) The daunting challenge for the time being is the validity both of our diagnostic categories and of our diagnostic systems. We have to completely rethink diagnosis and classification, that is to say, we cannot shrink from facing the big questions in psychiatry.

4) It appears that classifications based on cluster of symptoms have reached their limits. The attempt to carefully separate diseases through clinical description, in the hope that they will eventually be validated by other means, has not thus far succeeded. Within the current framework, true comorbidity and artefact can hardly be distinguished. Thus, we must strive to build an etiology-based classification.

5) There is no such a thing as atheoretical or apolitical classification. In fact, it is highly recommendable that the values espoused are explicitly admitted.

6) The reification of the categories may become an obstacle, both to teaching psychiatry (because they are easily mistaken for gospel), and to scientific research (because they can prevent the test of alternative formulations).

7) Comprehensive diagnostic schemes may be the best way of dealing with clinical complexity and to avoid reductionism. It offers the opportunity to combine standardized and personalized formulation. In this sense, diagnosis is more likely to be a true picture of the patient's health status.

8) The clinical utility of our current international classifications (ICD and DSM-IV - even though the latter was originally meant to be a national one) to improve care 


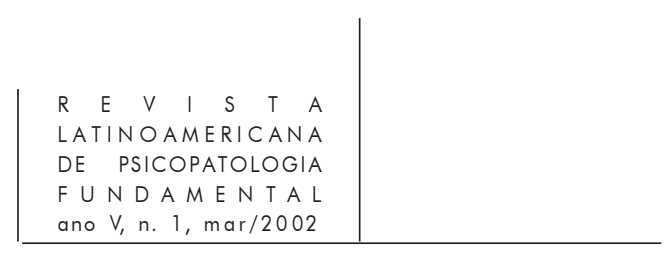

across different cultures has not yet been established. Despite this, most local classificatory systems (like the Chinese, for instance) are coming progressively less and less distinct from international ones.

Whether the general conclusions of that symposium will prove to be a point of inflexion in the history of psychiatric diagnostic classification or not, it is impossible to predict. It has been said that any classification is a daughter of its time and its circumstances (Mezzich and Almeida-Filho, 1994). Thus, we can only hope to see in the near future, with regards psychiatric diagnosis and classification, the simultaneous search for conceptual lucidity, cultural sensitivity and balance between scientific validity and clinical meaningfulness.

\section{References}

BANZATO, C.E.M. Sobre a distinção entre "critério" e "sintoma" na nosologia psiquiátrica. Revista Latinoamericana de Psicopatologia Fundamental, São Paulo, v. III, n. 3, p. 9-17, 2000.

BURTON, Robert. The Anatomy of Melancholy (1621), First Partition, Section I, Member 3, Subsection 4. New York: NYRB, 2001, p. 177.

Feinstein, A. How psychiatry lost its way. An open letter in reply to Paul McHugh. Int. J. Soc. Psychiatry., v. 46, n. 3, p. 232-5, 2000.

Guimón, J. The biases of psychiatric diagnosis. Brit. J. Psychiatry, n. 154 (suppl. 4), p. 33-7, 1989.

Hempel, C.G. Fundamentals of taxonomy. In: SAdler, J.Z., Wiggins, O.P., Schwartz, M. (eds.). Philosophical Perspectives on Psychiatric Diagnostic Classification. Baltimore: The Johns Hopkins University Press, 1994. p. 315-31.

Jablensky, A. Methodological issues in psychiatric classification. Brit. J. Psychiatry, n. 152 (suppl. 1), p. 15-20, 1988.

KendLer, K.S. Toward a scientific psychiatric nosology. Arch. Gen. Psychiatry, n. 47, p. 969-73, 1990.

MezZich, J.E., Almeida-Filho, N. Epidemiology and diagnostic systems in psychiatry. Acta Psychiatr. Scand., n. 90 (suppl. 385), p. 61-5, 1994.

Millon, T. Classification in psychopathology: rationale, alternatives, and standards. $J$. Abnorm. Psychol. v. 100, n. 3, p. 245-61, 1991.

Ріснот, P. Nosological models in psychiatry. Brit. J. Psychiatry, n. 164, p. 232-40, 1994.

SPITZER, M. Psychiatry, philosophy, and the problem of description. In: SPITZER, M., UeHLeIN, F.A., Oepen, G. (eds). Psychopathology and Philosophy. Berlin, Heidelberg: SpringerVerlag; 1988. p. 3-18.

VAN PraAg, H.M. Reconquest of the subjective: against the waning of psychiatric diagnosing. Brit. J. Psychiatry, n. 160, p. 266-71, 1992. 


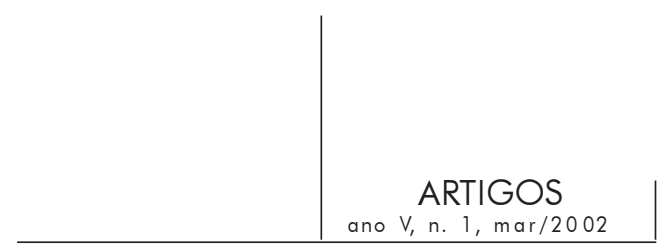

Resumos

O autor explora alguns dos desafios taxonômicos ainda enfrentados pelas classificações diagnósticas em psiquiatria, enfatizando aqueles mencionados por Hempel em seu influente Fundamentals on taxonomy. Novas tendências de pesquisa e de classificação também são apontadas.

Palavras-chave: Classificação, taxonomia, diagnóstico, psiquiatria

El autor explora algunos de los desafíos taxonómicos que son todavía enfrentados por las clasificaciones diagnósticas en psiquiatría, enfatizando los mencionados por Hempel en su influyente Fundamentals on taxonomy. Nuevas tendencias de investigación y clasificación son también proporcionadas.

Palabras clave: Clasificación, taxonomía, diagnóstico, psiquiatría

L'auteur explore quelques uns des défis taxonomiques encore rencontrés par les classifications diagnostiques en psychiatrie, en soulignant particulièrement ceux mentionnés par Hempel dans son ouvrage influent Fundamentals on taxonony. De nouvelles tendances de recherche et de classification sont également indiquées ici.

Mots Clés: Classification, taxonomie, diagnostic, psychiatrie

Versão inicial recebida em novembro de 2001

Aprovado para publicação em fevereiro de 2002 